\title{
Using sustainable development indicators (SDIs) for sustainability assessment of surface mining operations in the oil sands projects: applicability, usefulness and cost
}

\author{
C. A. Poveda \& M. G. Lipsett \\ Department of Mechanical Engineering, University of Alberta, Canada
}

\begin{abstract}
Sustainable development indicators (SDIs) can be found within currentlyexisting approaches, strategies, models, appraisals, and methodologies for environmental and sustainability assessment. Conceptually, the design and implementation of SDIs brings together different stakeholders towards finding the balance among economic, social, and environmental development; however, questions surround SDIs for the assessment of sustainability of projects (e.g. surface mining operations) or industries (e.g. oil and gas) for which the development of SDIs still is in its infancy: (1) Do the SDIs properly align theory with practice?; (2) Do the SDIs meet their intent?; and (3) Can the stakeholders and project proponents afford the implementation of SDIs? Individual efforts have been made to establish a set of SDIs by companies developing projects; and regulatory systems (in some way predecessors of SDIs) require certain levels of investment to meet a minimum level of performance, particularly on environmental grounds. But large industrial projects (such as oil sands projects, which include surface mining operations) do not have a comprehensive set of SDIs to benchmark sustainable performance and/or measure sustainable development. Questions remain regarding the rate at which extractive industry companies align with more sustainable practices, whether it is the applicability of SDIs, their degree of usefulness, or the costs of development and implementation of SDIs, or other factors. The present work analyzes the development and implementation of SDIs in surface mining operations for oil sands projects, highlights the benefits of using SDIs, proposes an alternative framework for SDI in the Canadian oil sands industry, and offers
\end{abstract}


recommendations for the use of SDIs to measure sustainable development of surface mining operations.

Keywords: sustainable development indicators, SDIs, sustainability assessment, rating systems, oil and gas, oil sands, sustainable development, energy consumption, surface mining operations.

\section{Introduction: surface mining operations and the Canadian oil sands}

The Canadian oil sands, an unconventional oil and gas resource, are located in the northern section of the provinces of Alberta and Saskatchewan in three main deposits: Athabasca, Peace River, and Cold Lake (as shown in Fig. 1). Out of approximately 174 billion barrels in reserves of Canadian oil, about 169 billion are located in the oil sands. Canada places third in global oil reserves after Saudi Arabia and Venezuela; however, it places first in unconventional oil and gas reserves since the other two deposits are conventional and heavy oil, respectively [1].

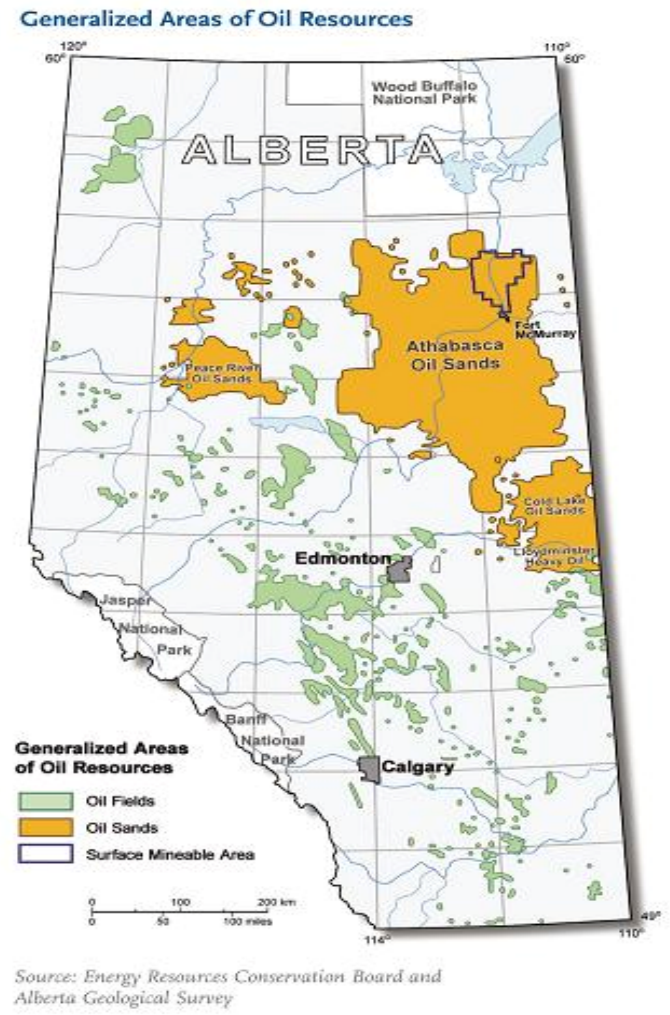

Figure 1: $\quad$ Oil sands deposits [2]. 
A mixture of sand, water, clay, and bitumen forms the oil sands. The bitumen extracted from the oil sands is too heavy to flow or be pumped; therefore, the bitumen must be diluted or heated. The extraction process can be achieved by two distinctive methods: in-situ (Latin, meaning "in place") or open-pit mining (e.g., surface mining). The bitumen extracted using the surface mining method is close to the surface and only counts for $20 \%$ of the total Canadian oil sands reserves. The other $80 \%$ is extracted using different in-situ techniques (e.g., steam-assisted gravity drainage [SAGD], cyclic steam stimulation [CSS], vapour recovery extraction [VAPEX]).

Surface mining operations are currently taking place in about $500 \mathrm{~km}^{2}$ out of the $140,000 \mathrm{~km}^{2}$ in which the oil sands are located. Only oil sands within 75 meters of the surface are extracted using the open-pit mining technique. For deeper oil sands developers use in-situ mining techniques as surface mining is not practical. Surface mining Out of the 1.6 million barrels per day (bbl/d) reached in $2010,53 \%$ of the crude bitumen production used the open-pit mining technique while the other $47 \%$ used in-situ methods [3].

Similar to coal mining operations, the surface mining process (as shown in Fig. 2) uses large electric and hydraulic shovels with capacities up to $45 \mathrm{~m}^{3}$ to
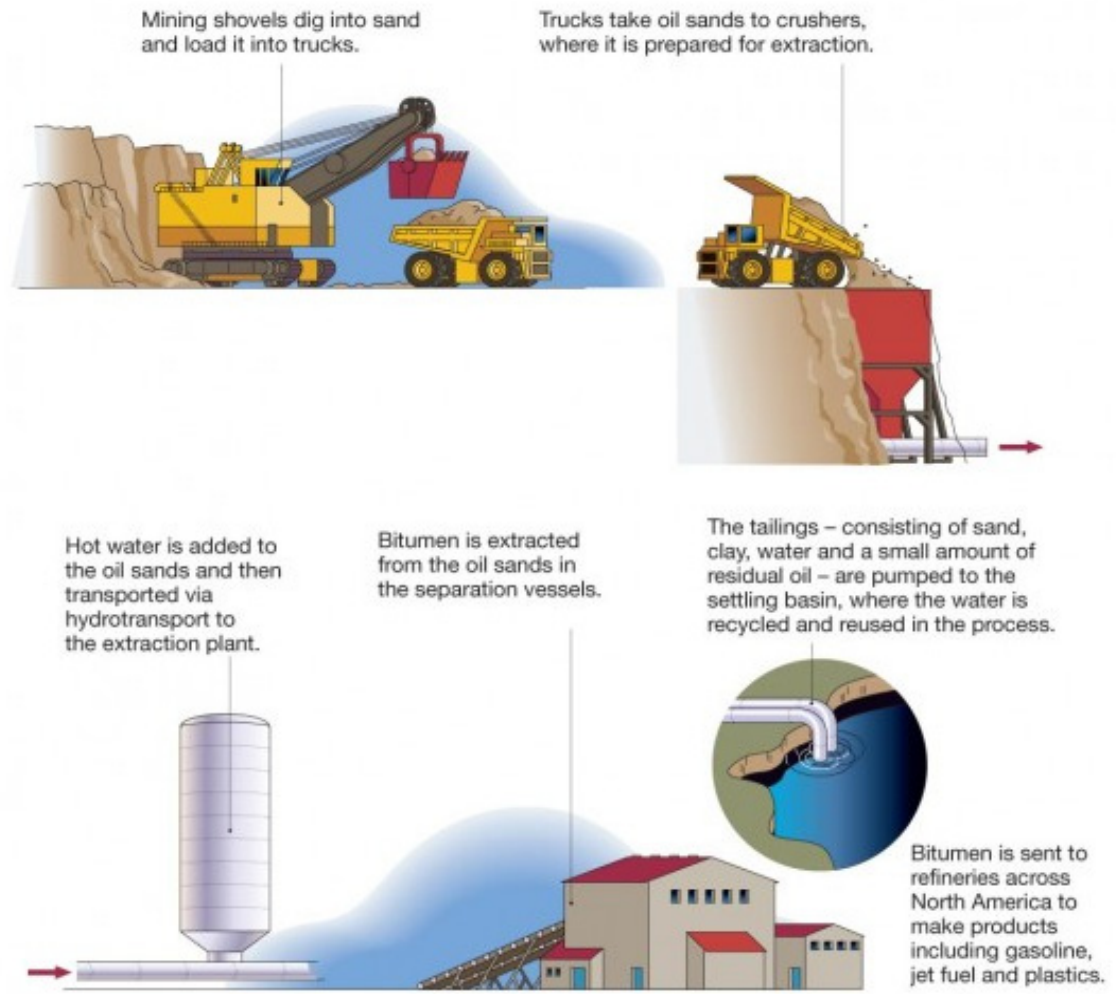

Figure 2: $\quad$ The surface mining process [4]. 
scoop the oil sand into trucks - with capacities up to 400 tons - that take the mixture to crushers where the material (i.e., large clumps of earth) is broken down. The mixture is diluted using water and diluent (naphthenic and paraffinic) to then be transported to a plant in which the bitumen is separated from the other components (e.g., clay, sand, water, chemicals). While the bitumen continues its course for upgrading and refining to become synthetic oil, the other components are sent to the tailings ponds areas after maximizing the water recycling process.

To produce one barrel of synthetic crude oil (SCO), about two tonnes of oil sands must be processed using the open-pit mining method. In comparison, the in-situ process represents a higher investment to extract the bitumen; however, no tailings ponds are required - a major area of concern from the environmental standpoint - since the sands remains in the ground and only bitumen is extracted.

The oil sands development has quickly increased during the past couple of decades. As a result, the resource and related projects have captured national and international attention, not only due to the size of the oil reserves, but also because of their diverse inherent impacts. Environmentally, the four areas of main concern are land use, tailings ponds, water use, and greenhouse gas (GHG) emissions. Even though environmental impacts are the most-talked-about area of concern arising from the oil sands development, economic, social, and health impacts are the cause of discomfort and discontent for local communities and a variety of stakeholders. Though the primary economic impacts may be perceived as "benefits" due to the large amounts of cash flow injected into the Canadian economy, there are secondary economic impacts to be considered. Socially, the development has caused great stress to the region due to the "boom town" effect, while health indicators provide evidence of the existence of issues that need to be addressed immediately.

Evidentially, diverse factors point out the need for creating a set of indicators to measure how sustainable the development of the oil sands is. The fast development of the region and extraction of the resource, the diverse impacts (i.e., economic, social, environmental, and health), the stakeholders' concerns, and the needs for new oil and gas resources (among other factors) demonstrate the necessity of finding a balance between the social, economic, and environmental needs of the present without affecting the needs of future generations. Moreover, measuring sustainability relies on finding a proper series of sustainable development indicators (SDI) to demonstrate the commitment of government, developers, local communities, and stakeholders in general to develop the resource in a responsible and sustainable manner. However, deciding on what to measure (i.e., indicators) and how to measure those indicators (i.e., metrics) is a complicated task for which the international scientific community still has not found common ground. This manuscript gives an interpretation of three factors - applicability, usefulness and cost - surrounding the application of SDIs to surface mining operations in the Canadian oil sands projects. 


\section{Sustainable development indicators (SDIs)}

Sustainable development indicators (SDIs) are also known as key performance indicators (KPIs) for sustainability. SDIs are used to measure the performance of organizations or projects regarding the different aspects (i.e., triple bottom line) of sustainability. The initial forces behind sustainable development (SD) have been the United Nations (UN) and national governments; therefore, the first sets of performance indicators have been developed focusing on national, regional, and community levels [5]. Moreover, linking the plans, policies, and programs of $\mathrm{SD}$ at the macro level with goals and objectives at the project and organizational levels is still a major hurdle for the international community - including governments, scientists, politicians, sociologists, and economists - to overcome.

The use of SDIs assists not only by identifying sustainability trends, but also by measuring the effectiveness and efficiency of SD policies, businesses, and projects; however, the use of SDIs is still in its infancy $[6,7]$. Nevertheless, a set of SDIs can be used as a measuring system of an organization while controlling its behaviour toward SD. Additionally, the implementation of appropriate measuring systems assists in the assessment of effective performance communication (achievement of goals and objectives) and responsiveness to stakeholder concerns [8].

In the literature, two distinct forms of indicators are found: qualitative and quantitative. The type of indicators used is usually mandated by the objective of the measure; however, quantitative indicators are applied more often [9], which points towards the desire to avoid the subjectivity that any qualitative measurement intrinsically possesses. Although SDIs are the most commonly used tool to assess SD, the design of SDIs still has challenges to overcome. The triple bottom line, known as the three pillars of sustainability (i.e., social, economic, and environmental), is known globally but not universally accepted. Additionally, the starting point in the design of SDIs is to define what to measure (i.e., indicators), followed by how to measure the indicators (i.e., metrics); in both instances, the debate among different groups - environmentalists, politicians, sociologists, and economists, among others - has not reached consensus on a unified set of indicators for SD.

While the use of indicators facilitates understanding of the performance of organizations or projects toward SD, the action of reporting adds to the debate. SD performance can be presented using indicators or a combination of indicators (i.e., indices). An indicator may be taken as a simplistic form of reporting sustainability performance, and may be used to hide the real issues of the organization or project with regard to sustainability, which raises issues of transparency and credibility. Also, a set of indicators can be designed on a project, organization, or industry basis. Since SDIs are non-compulsory tools, the use of a set of indicators designed to meet the needs of a certain industry relies on the commitment of an organization to report its performance. A set of indicators designed for an industry (e.g., mining) may not meet the needs of all members (as different processes are used for each type of material mined); therefore, the design and use of a set of indicators on an organizational level (i.e., 
a set of indicators measuring overall sustainability performance in organizations with a variety of projects in their portfolio) represents a viable alternative, but adds the undesired inability to benchmark performance among organizations and/or projects within the same industry.

Therefore, a set of indicators must be designed for a sector of an industry that manages similar projects (e.g., the oil sands); a project basis set of indicators must not only follow the industry guidelines and address the different stakeholders' needs, but must also meet the requirements and fundamentals (e.g., the triple bottom line) of SD in a balanced approach.

The mining industry has moved towards a more sustainable path. Different organizations have developed and/or are implementing a series of sustainability frameworks. After a two-year consultation process, the International Council on Mining and Minerals (ICMM) implemented a SD framework consisting of integrating 10 principles with 7 supporting position statements, transparent and accountable reporting systems, and a third-party verification process. The Institute of Materials, Minerals, and Mining (IOM3) highlights the standards (e.g., ISO, CEN, BSI) supporting SD during the life cycle of manufactured products. Additionally, IOM3 is currently engaged with a variety of programs and initiatives that promote SD.

Nationally, the Mining Association of Canada (MAC) and the Canadian Institute of Mining, Metallurgy, and Petroleum (CIM) are presently working towards setting processes and practices for sustainable mining operations. Moreover, MAC has developed a series of guiding principles and performance elements under the Toward Sustainable Mining (TSM) initiative. TSM - a mandate for the MAC members - contains a series of indicators that support the guiding principles and address the areas of crisis management, energy and GHG emissions management, tailings management, biodiversity conservation management, safety and health, and Aboriginal relations and community outreach [10]. Other national and international programs and initiatives in the mining industry for issues related to SD include, but are not limited to: the Whitehorse Mining Initiative; Mine Environment Neutral Drainage (MEND); the Green Mining Initiative (GMI); the Canada Mining Innovation Council (CMIC); Mining, Minerals, and Sustainable Development (MMSD); the International Council on Mining and Metals (ICMM); and the United Nations Environment Programme's Mineral Resources Forum (UNEP MRF).

Undeniably, the mining industry has taken steps toward more sustainable and responsible practices; however, as previously discussed, the programs and initiatives are still at the industry level. The mining industry in Canada not only consists of oil sands reserves, but also gold, diamonds, zinc, uranium, aluminium, etc. Therefore, industry-wide initiatives for sustainability may overlook the individual impacts that each mined material carries in each stage of its life cycle. As a result, the development of the Canadian oil sands requires a project-based (i.e., similar processes are followed by developing companies) set of SDIs (i.e., a measuring system), not only to measure sustainability performance, but also to assist developers, government, local communities, and other stakeholders in the decision-making and benchmarking performance 
processes. The development and implementation of SDI analysis requires answering questions such as: (1) Do the SDIs properly align theory with practice? (i.e., applicability), (2) Do the SDIs meet their intent? (e.g., usefulness), and (3) Can the stakeholders and project proponents afford the implementation of SDIs? (e.g., cost).

\subsection{Applicability}

Corporate performance is transforming. While financial measures continue to be a crucial aspect, non-financial measures are increasingly gaining relevance for corporate sustainability [11]. The application of environmental indicators is a reflection of the advances made in research, education, and stakeholder engagement. Furthermore, interest in the use of non-financial measures is due to the growing interest different stakeholders, including investors and clients, are taking in additional information regarding the organization's performance [12]. As a result, organizations implement measurement systems to assist with the transformation; however, a major hurdle encountered in the implementation of measurement systems consists of integrating financial and non-financial measures to reflect an organization's strategic objectives [13]. The use of KPIs for sustainability (indicators) as a measuring system assists assessing the financial and non-financial performance of an organization or project. Then, the success of integrating financial and non-financial measures (i.e., indicators) relies on designing the metrics for the selected set of indicators.

Although organizations are identifying the need for measurement systems, the road to implementation may not be easy. Robinson et al. [11] state the resistance to change and the degree to which construction organizations fail when implementing innovative approaches to improve future business performance; however, the increasing use of KPIs "evidence the cultural change and the progress made in performance improvement measurement and reporting" [14]. As sustainability continues emerging in businesses and corporate cultures, the use of KPIs assists in identifying those areas in need of improvement while linking the organizations' strategic goals and objectives and facilitating benchmarking against best practices and competitors. Furthermore, the benchmarking characteristics of KPIs for sustainability contribute to the transformation of corporate performance of an entire industry, as "benchmarking tools measure issues such as people, design, environmental performance, and general business performance" [14]. Nevertheless, the development and implementation of KPIs for sustainability depends on the degree to which the theory supports the practical application of measurement systems.

Although the theory of SDIs (selection of indicators and metrics) is not fully developed in terms of the level of development of each pillar of sustainability, the practice seems to align with the theory, and is reflected by the percentage of indicators used in a given set of SDIs to report the organization's and/or project's social, economic, and/or environmental performance. Additionally, because of the usual limited number of indicators used, a set of SDIs may not accurately reflect the proper measurement of every intended aspect included in the principles and fundamentals of SD. Nevertheless, sustainability is still in its 
infant stages, and its three pillars are in different levels of development. The design and implementation of SDIs develops in parallel with the understanding of each pillar of sustainability and the interconnections between them. While environmental indicators are the primary type used to report sustainability performance, social and economic indicators have a limited but growing presence.

The current sets of indicators for mining operations contain a handful of indicators, which only address some aspects of sustainability. While environmental impacts and aspects are fairly well-understood and several tools are available to measure environmental indicators (i.e., metrics), the social and economic pillars of sustainability are still far behind; therefore, sets of indicators often focus heavily on measuring environmental performance. As a result, the development and application of a larger range of indicators to measure the sustainability of mining projects is required in order to address the different stakeholders' needs. Since some sectors of stakeholders have requested tougher regulations, the government has been forced to act; however, the use of SDIs is not currently regulated. Nevertheless, the use of SDIs and transparent reporting assists developers in obtaining the "social license" to operate, which is of high priority from a corporate social responsibility perspective.

The level of practical implementation may not fully reflect the theoretical advances being made regarding each pillar of sustainability. Since the use of SDIs is not regulated, organizations' reporting activities are non-compulsory; therefore, organizations and projects may report those indicators that reflect the areas of good performance, and the only pressure developers have to report performance consists of obtaining the "social license" to operate. Mining projects are large by nature, and their related impacts cover a range of issues (e.g., environmental, social, economic, political, and health-related). For example, the initiative Towards Sustainable Mining (TSM) developed by MAC a mandate for its members - reports on six key areas of operation performance, and is currently working on developing specific indicators for mine closure [10]. In 2011, 20 MAC members reported their performance, which is measured at the facility level, and 6 of those organizations underwent external verification. Even though the TSM initiative demonstrates the industry's first steps toward more sustainably developed mining operations, the current set of SDIs leaves out areas of SD of crucial importance in order to meet the needs of stakeholders and find a true balance among the social, economic, and environmental pillars of SD. The 6 TSM areas of operation performance are divided as follows: 3 environmental areas (i.e., tailings management, energy use and GHG emissions management, and biodiversity conservation management), 2 social areas (i.e., Aboriginal and community outreach, safety and health), and 1 integrated area (i.e., crisis management), and assist companies in leveraging best practices and critically assessing business performance. As an example, a closer look into the 2 social areas of operation performance included in the TSM initiative illustrates the need for developing a more complete set of SDIs addressing a larger range of social impacts due to the development of mining projects and operations: Aboriginal and community outreach is measured using four performance indicators 
(i.e., 1. community of interest (COI) identification, 2. effective COI engagement and dialogue, 3. COI response mechanism, and 4. reporting), and safety and health uses five performance indicators (i.e., 1. policy, commitment, and accountability; 2. planning, implementation, and operation; 3. training, behaviour, and culture; 4. monitoring and reporting; and 5. performance) [10].

\subsection{Usefulness}

The increased awareness in measuring the impact on society is in response not only to the need to minimize the environmental effects of construction activities, but also as part of a growing corporate sustainability agenda to give something positive back to society [11]. Therefore, the usefulness of SDIs for assessing the sustainability of surface mining operations in the oil sands projects can be analyzed from different perspectives: benchmarking, continuous improvement processes, business performance measurement, corporate social responsibility, and stakeholder engagement, among others.

As a benchmarking tool, a set of SDIs (or KPIs for sustainability) supports business improvement. The benchmarking process questions who performs better, why they are performing better, and how a company can improve. Because benchmarking is an ongoing process [14], a set of SDIs facilitates organizations and projects reporting performance activities as a continuous activity instead of being a sporadic task of performance measurement (e.g., audit process). Hřebíček et al. [15] state that KPIs help organizations to implement strategies by linking various levels of an organization (e.g., organizational units, departments, and individuals) with clearly-defined targets and benchmarks.

Benchmarking performance does not concentrate on the organization's or project's performance; instead, to realistically improve performance, the comparisons should be made with others (e.g., external organizations or projects performing similar activities) [14]. It is expected that organizations will need to use environmental KPIs to adequately capture the link between environmental, social, and economic performance [15]. Presently, mining operations for oil sands projects has limited tools to benchmark performance. The SDIs used to measure sustainability performance are limited not only in number but also in scope and/or do not properly isolate the surface mining process (i.e., SDIs are used to report performance of the overall facility, which includes processes other than mining). In the case of the mining industry, the TSM is an industry-wide tool that not only does not differentiate the material mined, but also uses a limited number of SDIs; therefore, it does not address the specific impacts (i.e., social, economic, environmental, health) carried by surface mining operations in the oil sands projects.

Business performance measurement models facilitate continuous improvement. They provide a balance between short- and long-term objectives, financial and non-financial measures, and external and internal performance [11]. Understandably, organizations are turning to the use of SDIs not only because of the 360-degree performance evaluation that can be accomplished, but also because they can help demonstrate a commitment to performance improvement, corporate reporting responsibility, and stakeholder engagement 
qualities. Moreover, measuring performance not only identifies the gaps between current and desired performance, but also assists the improvement process by indicating any progress towards closing the gaps [16]. Bititci and Nudurupati [17] explain that performance measurement should assist organizations in identifying key areas that need improvement, diagnosing and analyzing the reasons behind low performance, planning and implementing changes necessary to improve performance in a quantifiable or measurable way, monitoring the results to find whether they achieved the expected results, and developing a closed-loop control system to promote continuous improvement.

The need for performance evaluation and improvement in mining operations for the oil sands projects is evidence of disconformity among certain groups of stakeholders. Either the developers are not addressing the stakeholders' needs, which can be demonstrated through performance measurement (i.e., the use of inadequate or limited SDIs), or there are deficiencies in the stakeholder engagement during the projects life cycle, including the performance reporting stage. In fact, progress in the improvement process can be demonstrated through changes in behaviour and attitude, improvements in the key operational and business performance indicators, and the degree to which quality improvement projects are aligned with the company's articulated strategies, policies and guidelines [18]. Nevertheless, improvements made within an organization or project must be effectively communicated, not only to stockholders but also to stakeholders. Large projects with a variety of stakeholders (e.g., surface mining operations for oil sands projects) are sensitive by nature due to the intrinsic impacts present during their development. Therefore, as occurs in other decisionmaking processes, the identification, development, and implementation of SDIs requires stakeholder participation through effective engagement, with the aim of increasing the opportunities to accomplish the intended goals and objectives. The stakeholders' participation offers credibility to the process and accountability of the parties involved; the involvement of stakeholders for mining operations in the oil sands projects has transformed from one-sided or limited to a multicriteria integrated participatory process.

\subsection{Cost}

The cost of implementing SDIs can be analysed based on the benefits (i.e., wealth and profits) for organizations and the actual costs of setting the measurement systems to monitor and control sustainable development performance.

Performance measurement through continuous improvement methodologies provides organizations and projects with the advantage of demonstrating civic leadership in sustainability. Additionally, continuous improvement adds to an organization's competitiveness [19] as a variety of clients - especially within the public sector - are seeking to work with organizations that are willing to demonstrate their commitment to continuous improvement [14]. Therefore, organizations not only are looking to win work through the implementation of KPIs systems, but also gain advantages in reporting wider projects requirements besides time and cost [14]. 
From the stakeholder's standpoint, a company can endure over time if it is able to build and maintain sustainable and durable relationships with all members of its stakeholder network. Those ties between organizations and the stakeholder can be built but also strengthened through stakeholder engagement to accomplish SD goals and objectives. From this point of view, a company creates value when it adopts a managerial approach that is sustainability-oriented [8]; furthermore, the sustainability of a firm depends on the sustainability of its stakeholder relationships. Companies need appropriate systems to measure and control their own behaviour in order to assess whether they are responding to stakeholder concerns in an effective way, and in order to communicate and demonstrate the results achieved [8].

For organizations, projects, government, communities, and stakeholders in general, it is usually profitable to "go green" and to promote sustainable practices (both financial and non-financial). Bouchery et al. [20] use the concept of eco-socio-efficiency as a balance of economic, environmental, and social performance, and argue that the current situation is generally eco-socioinefficient, with some sporadic exceptions. Therefore, companies are exploring the concept of sustainable development, seeking to integrate their pursuit of profitable growth with the assurance of environmental protection and quality of life for present and future generations. As a result, some companies are beginning to make significant changes in their policies, commitments, and business strategies [21].

From the other side of the spectrum, organizations must absorb the cost of implementing a measurement system (i.e., SDIs or KPIs for sustainability). While some organizations can fully implement a measurement system, others can (and must, based on the organization's size) use external verification services. With either alternative the organization chooses, third-party firm verifications (i.e., audits) are to be considered, and the organization must be willing to participate. Based on the limitations of the existing SDIs for assessing the sustainability of surface mining operations for the oil sands projects previously discussed, an independent process for the identification, development, and implementation of an improved set of SDIs must be created by a multidisciplinary team and stakeholder participation, with the aim of having a transparent process to assess SD performance.

\section{Conclusions}

The development of a set of SDIs for surface mining operations in the oil sands projects is applicable, useful, and its cost is manageable and justified. The oil and gas industry must transform to meet the stakeholder demands. The construction industry went through a similar transformation process demonstrating the benefits of SDIs and the implementation of measurement rating systems implementation. Exploitation of natural resources - nonrenewable, in the case of the Canadian oil sands - to meet the oil and gas needs of the present generation cannot be accomplished at expense of irreparable damages to the environment and society, regardless of the initial economic 
benefits (as negative economic impacts also occur). Unconventional oil and gas resources extraction and processing contain higher negative impacts (especially environmental) than conventional resources. As the need for finding alternative oil and gas resources grows due to the scarcity of conventional resources, proper tools (e.g., SDIs and sustainability rating systems) must be created and used in order to develop the resources in a socially, environmentally, and economically sustainable manner.

\section{References}

[1] Canadian Association of Petroleum Producers-CAPP. (2012). Energy. Retrieve from http://www.capp.ca/canadaIndustry/oilSands/EnergyEconomy/energy/Pages/default.aspx. December 2012

[2] Alberta Energy. (2012). Launching Alberta's Energy Future, Provincial Energy Strategy. Retrieve from http://www.energy.alberta.ca/Initiatives/ 1505.asp. December 2012

[3] Alberta Energy. (2012). Facts and Statistics. Retrieve from http://www.energy.alberta.ca/OilSands/791.asp. December 2012

[4] Canadian Association of Petroleum Producers-CAPP. (2012). Recovering the Oil. Retrieve from http://appstore.capp.ca/oilsands/page/recovering-theoil-2012-01-23-03-01-01. December 2012

[5] Labuschagne, C., Brent, A.C., Van Erck, P.R.G. (2005). Assessing the Sustainability Performances of Industries. J. Clean. Prod. Vol 13, pp. 373-385

[6] MacGillivray, A. and Zadek, S. (1995). Accounting for change: indicators for sustainable development, New Economic Foundation, London

[7] Bell, S. and Mores, S. (2003). Measuring Sustainability Learning from Doing, Earthscan, London

[8] Perrini, F. and Tencati, A. (2006). Sustainability and Stakeholder Management: The Need for New Corporate Performance Evaluation and Reporting Systems. Business Strategy and the Environment. Vol 15, pp. 296-308

[9] Gallopin, G. C. (1997). Indicators and their Use: Information for decisionmaking, in Moldan, B., Billhartz, S. and Matravers, R. (eds) Sustainability Indicators: A Report on the Project on Indicators of Sustainable Development, John Wiley and Sons, Chichester, pp. 13-27

[10] The Mining Association of Canada. (2012). Towards Sustainable Mining. Retrieve from http://www.mining.ca/site/index.php/en/towards-sustainablemining.html. January 2013

[11] Robinson, H. S., Anumba, C. J., Carrillo, P. M. and Al-Ghassani, A. M. (2005). Business Performance Measurement Practices in Construction Engineering Organisations. Measuring Business Excellence, Vol. 9 (1), pp. $13-22$

[12] DiPiazza, S. A., (Jr) and Eccles, R. G. (2002). Building Public Trust: The Future of Corporate Reporting, John Wiley and Sons 
[13] Butler, A., Letza, S. R. and Neale, B. (1997). Linking the Balance Scorecard to Strategy. Long Range Planning, Vol 30 (2), pp. 242-253

[14] Swan, W and Kyng, E. (2004). An Introduction to Key Performance Indicators. Centre for Construction Innovation

[15] Hřebíček, J., Misařová, P. and Hyršlová, J. (2007). Environmental Key Performance Indicators and Corporate Reporting. In International conference EA-SDI 2007. Environmental Accounting and Sustainable Development Indicators. Praha: Universita Jana Evangelisty Purkyně, pp. 147.-155

[16] Weber, A. and Thomas, R. (2005). Key Performance Indicators. Ivara Corporation. Burlington, Ontario

[17] Bititci, U. S. and Nudurupati, S. S. (Undated). Using Performance Measurement to Drive Continuous Improvement. Centre for Strategic Manufacturing, DMEM, University of Strathclyde, Glasgow

[18] Dale, B. G. (1996). Sustaining a Process of Continuous Improvement: Definition and Key Factors. The TQM Magazine. Vol 8 (2), pp. 49-51

[19] Hyland, P.W., Mellor, R. and Sloan, T. (2007). Performance Measurement and Continuous Improvement: Are They Linked to Manufacturing Strategy? Int. J. Technology Management. Vol 37 (3/1). pp. 237-246

[20] Bouchery, Y., Ghaffari, A. and Jemai, Z. (2010). Key Performance Indicators for Sustainable Distribution Supply Chains: Set Building Methodology and Application. Cahiers de recherche 2010-08, Laboratoire Génie Industriel, Ecole Centrale Paris

[21] Defra-Department for Environment, Food and Rural Affairs (2006). Environmental Key Performance Indicators: Reporting Guidelines for UK Business. Department for Environment, Food and Rural Affairs. London, UK 